\title{
SUBSTANCE ABUSE, DEPENDENCE AND THE WORKPLACE: A LITERATURE OVERVIEW
}

\section{Breggie Smook, Marie Ubbink, Elma Ryke, Herman Strydom}

\section{INTRODUCTION}

This article investigates the prevalence and negative impact of substance abuse and dependence with specific reference to the workplace. It looks at the directives of the National Drug Master Plan (NDMP) for combating substance abuse in South Africa; the legislative requirements for managing substance abuse in the workplace; and guidelines on workplace substance-abuse policies. Various intervention measures to combat substance abuse in the workplace, including prevention and treatment programmes, are discussed, as is the role of employee assistance programmes (EAPs) as a means of inhouse intervention. Specialist treatment and rehabilitation facilities such as in- and outpatient treatment centres as external resources are also covered. Findings on treatment outcomes are discussed to indicate the potential benefits of substance-abuse treatment for employers as well as employees. The article ends with a recommendation for a situation analysis to explore the specific needs of employers in addressing substance abuse in the workplace.

Although most research indicates that alcohol abuse is a greater dependency problem than the abuse of other substances, McCann, Harker Burnhams, Albertyn and Bhoola (2011:32) recommend the inclusion of both types under the same programme for prevention and treatment purposes. This article focuses on substance abuse and dependence and includes alcohol as well as other substances. Findings that refer to a specific substance are indicated as such.

Figure 1 (adapted from Creswell, 2003:40) shows the key focus areas covered in the article.

FIGURE 1

KEY FOCUS AREAS IN THE LITERATURE OVERVIEW

\begin{tabular}{|c|c|c|c|}
\hline & \multicolumn{2}{|c|}{ SUBSTANCEABUSE and the WORKPLACE } & \\
\hline $\begin{array}{l}\text { SUBSTANCE ABUSE } \\
\text { Prevalence } \\
\text { Impact }\end{array}$ & $\begin{array}{l}\text { NATIONAL PLAN \& LEGISLATION } \\
\text { National Drug Master Plan } \\
\text { Legislation }\end{array}$ & WORKPLACE & $\begin{array}{l}\text { INTERVENTION } \\
\text { Prevention \& treatment } \\
\text { In-house intervention: EAP } \\
\text { Specialist treatment } \\
\text { Rehabilitation facilities } \\
\text { Treatment outcomes }\end{array}$ \\
\hline
\end{tabular}




\section{PROBLEM STATEMENT}

Substance abuse and dependence are a global concern and very costly to all societies where they occur (Hitzeroth \& Kramer, 2010:13; Miller \& Weisner, 2002:3). Improved economic opportunities in South Africa since 1994 have led to a rise in alcohol-related problems. The trafficking of substances and the number of people in the workplace seeking treatment for substance-abuse problems have also increased over this period (McCann et al., 2011:44; UNODC, 2012:92-93).

Statistics on substance abuse in South Africa were released by the Central Drug Authority (CDA) at the launch of the United Nations World Drug Report in 2009 (Anon, 2009:1), where it was revealed that the consumption of substances in South Africa is twice the world norm; $15 \%$ of South Africa's population has a substance-related problem; substance abuse is costing South Africa R20 billion a year and poses a bigger threat to the future of the country than the HIV and AIDS pandemic; South Africa is regarded as one of the drug capitals and top ten narcotics and alcohol abuse centres of the world. Alcohol remains the most commonly abused substance in South Africa followed by cannabis (CDA, 2010/2011:33-34; Eberlein, 2010:32; McCann et al., 2011:46; NDMP, 2012-2016:3,26,36; SACENDU, 2012a:1). Regarding illicit substance use, it is estimated that there are between 119 million and 224 million cannabis users worldwide (UNODC, 2012:2). Although cannabis use is stable and even declining in some developed countries, it is increasing in many developing countries (UNODC, 2012:5). Cannabis use in Africa is reported to be much higher than the global average (UNODC, 2012:17). The CDA annual report (2010/2011:34) reveals that 2.2 million people or $8.4 \%$ of the population in South Africa used cannabis in 2004 against the global norm of 4\%. In 2008 approximately 3.2 million cannabis users were recorded in South Africa, indicating an increase of nearly 20\% since 2004. According to Hitzeroth and Kramer (2010:39), a recent study among mine workers in South Africa revealed cannabis use of $9.1 \%$.

Regarding alcohol use, the World Health Organisation (WHO) stresses the heavy burden in most countries of diseases and deaths attributable to alcohol consumption. Almost 4\% of all deaths worldwide can be linked to alcohol, which is greater than deaths caused by HIV and AIDS, violence or tuberculosis (WHO, 2011:20). Another measurable pattern of alcohol consumption risk is heavy episodic drinking or binge drinking, which is fairly high in South Africa (Eberlein, 2010:33; WHO, 2011:15-17). A review in 2009 of harmful drinking patterns and levels of consumption in 20 African countries showed that, in terms of the proportion of heavy drinkers as a percentage of current drinkers, South Africa ranked fourth highest (McCann et al., 2011:23).

Against this background, the following questions guided this article: What are the main issues regarding substance abuse in the workplace? What are the legal requirements for managing the problem in the workplace? What resources are available to employers to deal with the problem in the workplace? 


\section{SUBSTANCE ABUSE}

\section{Prevalence}

National data on substance abuse in the workplace are currently unavailable; however, the literature and data sources point to an increase in substance abuse among the employed in South Africa (Grobler, Wärnich, Carrell, Elbert \& Hatfield, 2006:404; McCann et al., 2011:45). Research (Hitzeroth \& Kramer, 2010:38; McCann et al., 2011:25) done among farm workers and at a defence force clinic in South Africa revealed high patterns of hazardous drinking. Also, 9.3\% of mine workers who participated in a study in South Africa were found to use alcohol on a daily basis; $15.3 \%$ of them were alcohol dependent (Hitzeroth \& Kramer, 2010:38). Data collected by the South African Medical Research Council (MRC) indicate that referrals by employers for substance abuse problems at treatment centres are mainly for alcohol-related problems (McCann et al., 2011:25-26). Grobler et al. (2006:404) refer to the growing concern of employers about the increase in substance abuse in the workplace. Estimates on the prevalence of alcohol-dependence problems in the workplace range from 5\% to $35 \%$, and other substance problems from 7\% to 20\% (Eberlein, 2010:31-37; Grobler et al., 2006:401; Hitzeroth \& Kramer, 2010:38-39; McCann et al., 2011:45).

\section{Impact}

The economic impact of substance abuse on employers amounts to millions of rands annually in South Africa. Substance abuse by employees on-site and/or off-site inevitably results in decreased productivity, work errors, wasted materials and tardiness, all of which translate into massive losses each year (Eberlein, 2010:35-36; Grobler et al., 2006:401-404; ICAP, 2013; NDMP, 2012-2016:27-36). It is estimated that over 50\% of accidents at the workplace are substance-abuse related; that theft and other criminal activities at work treble as a result of substance abuse; and that undetected substance abusers cost employers a further 25\% of their annual wages (McCann et al., 2011:48).

Above-average absenteeism from work, injuries, substandard levels of productivity and poor-quality performance of employees with substance-abuse problems are also actual costs to companies (Eberlein, 2010:178-184; Grobler et al., 2006:401; Parry \& Bennetts, 1998:57-76). Comprehensive data on substance-abuse-related absenteeism are not available for South Africa; however, the results from a sample of male alcoholics, of whom $67 \%$ were employed, revealed that the respondents each lost an average of 86 working days annually as a result of absence; $66 \%$ of the sample was often late for work; $61 \%$ reported Monday-morning absenteeism; and 62\% occasionally drank alcohol at work, while 12\% did so regularly (McCann et al., 2011:24-25). Grobler et al. (2006:401) report that alcoholic employees are on average absent two to four times more frequently than non-alcoholic employees, and they cause two to four times more on-thejob accidents. Other findings confirm that harmful drinking is associated with greater absenteeism (ICAP, 2013).

Compared to dependence, substance abuse is less identifiable and has greater cost implications for employers. McCann et al. (2011:1-3) therefore state that the main problem in the workplace is not so much dependence as abuse. These authors add that a 
higher number of accidents and instances of absenteeism are attributable to low-tomoderate drinkers, who account for more than half of the workforce. Far more moderate, heavy and troubled problem drinkers than dependent drinkers are encountered in the workplace. An estimated $85 \%$ of employees consume alcohol, of whom $30 \%$ will be heavy, excessive and/or problem drinkers, while approximately $6-16 \%$ will be dependent drinkers (McCann et al., 2011:2,45). (See Figure 2 in this regard). According to the International Labour Organisation, $60-70 \%$ of workplace problems are caused by moderate to occasional substance abusers (McCann et al., 2011:289).

The negative consequences of the link between substance use and HIV and AIDS have consistently been pointed out (Barnett \& Whiteside, 2006:86; McCann et al., 2011:172173; NDMP, 2012-2016:29; Rose \& Zweben, 2002:148-149; UNODC, 2012:97; Van Dyk, 2005:298). A high prevalence of HIV infection is reported among individuals with substance-abuse problems as a result of greater sexually risky behaviour and infection through contaminated needles. The negative influence of substance use on the immune system, the delay in recovery from opportunistic diseases, and interference with the absorption of nutrients during the treatment of HIV and AIDS have also been confirmed (Barnett \& Whiteside, 2006:86; McCann et al., 2011:172-173; Rose \& Zweben, 2002:148-149; Van Dyk, 2005:298). Given that companies are already encountering increased labour costs as a result of 37\% HIV-related absenteeism, the link with substance abuse places additional pressure on the business sector (Barnett $\&$ Whiteside, 2006:264).

Another group identified in the NDMP (2012-2016:74) as one of the priority target groups is the "occupational groups at risk". Some occupational groups are regarded as high-risk and safety-sensitive and include occupations that pose a significant lifethreatening danger to the employees concerned, their fellow employees and/or the general public (Pelser, 2011:10). Sectors such as public transport, the construction and engineering industry, the security industry and financial institutions are considered especially vulnerable to the impact of substance abuse (McCann et al., 2011:70). Alcohol and other substances are often used to reduce tension and promote a feeling of wellbeing. This could explain the link between substance abuse and individuals employed in high-risk occupations or in jobs with high work demands and high stress levels (McCann et al., 2011:7). Those in high-risk and safety-sensitive occupations are at even greater risk when substances are used during working hours, or when employees report for duty while under the influence of a substance.

To summarise, South Africa is facing an increase in substance abuse among employed people in the country. The increase in cannabis users and alcohol abusers, especially regarding hazardous drinking patterns, is a major concern. Substance-abuse-related accidents in the workplace, theft and other criminal activities at work as a result of substance abuse, and above-average absenteeism from work as a result of substance abuse, add significantly to the costs of employers. Occupations at risk - and which are at even greater risk when substances are used - and the link between substance abuse and HIV and AIDS place additional pressure on employers. 


\section{NATIONAL PLAN AND LEGISLATION}

The UNODC (United Nations Office on Drugs and Crime, 2012) and the WHO (2011) have called on member states, including South Africa, to develop preventative programmes and reduce the harmful consequences of substance abuse in their own countries. The WHO (2011:53) has stressed the importance of formal treatment policies and procedures in combating substance abuse. The South African National Drug Master Plan (NDMP) and labour legislation provide national directives to promote effective management of substance abuse in the workplace (NDMP, 2012-2016:68). The NDMP and relevant legislation are discussed below.

\section{South African drug master plan (NDMP)}

The NDMP was formulated by the CDA (Central Drug Authority) in terms of the Prevention of and Treatment for Substance Abuse Act (Act 70 of 2008) in part to meet South Africa's responsibilities to the UNODC in respect of combating substance abuse in the country (NDMP, 2012-2016:10). The CDA is the statutory body authorised in terms of the Act to direct, guide and oversee the implementation of the NDMP as well as to monitor and evaluate the initiatives of all relevant stakeholders in their endeavours to realise the vision of the NDMP: "A substance abuse free South Africa" (NDMP, 20122016:68). The CDA annual report (2010/2011:7-9) covers resolutions aimed at combating substance abuse in South Africa that were formulated during the $2^{\text {nd }}$ Biennial Anti-substance Abuse Summit in 2011. These resolutions are included in the NDMP, and those relevant to this article are listed below (NDMP, 2012-2016:85;93-94).

- Intensifying campaigns to inform and educate people about the dangers of substance abuse;

- Implementing comprehensive prevention programmes;

- Implementing a care and public health approach that provides for prevention, early identification, treatment, rehabilitation and aftercare services;

- Strengthening aftercare services;

- Increasing the provision of rehabilitation services.

Certain key changes were identified during the review of the NDMP (2006-2011) and included in the new NDMP (2012-2016:3-4):

- A shift from a supply reduction approach to one of primary prevention;

- A change from a top-down to a bottom-up approach;

- The application of research and development to meet the predicted needs and future changes in the field of substance abuse;

- The introduction of proper monitoring and evaluation (M\&E) measures.

An integrated, balanced approach to combat substance abuse in South Africa is advocated and includes the following strategies (NDMP, 2012-2016:21): 
- Demand reduction - reducing the need for substances through a variety of means including prevention, education and the imposition of restrictions on the use of substances;

- Supply reduction - reducing the quantity of substances available on the market;

- Harm reduction - limiting the damage caused to individuals who are already addicted through treatment, aftercare and reintegration into society.

The application of this integrated strategy requires harmonising and enforcing laws and policies to facilitate effective governance of substance abuse in South Africa (NDMP, 2012-2016:22).

\section{LEGISLATION}

Several South African Acts stipulate labour requirements for dealing with substance abuse and dependence in the workplace and emphasise the obligations of employers as well as employees in this regard. The Acts relevant to the topic under discussion here outlined below.

The Constitution of the Republic of South Africa (108 of 1996) stipulates that no unfair discrimination directly or indirectly may be practised on the grounds of disability, including substance abuse dependence, which can be regarded as a certain kind of incapacity (RSA, 1996).

The Prevention of and Treatment for Substance Abuse Act (70 of 2008) acknowledges that substance abuse is a chronic and relapsing medical condition (RSA, 2008). However, the link between HIV and AIDS and substance abuse is not sufficiently stated in the said Act (McCann et al., 2011:195), whereas clear and consistent associations are drawn between substance abuse and HIV and AIDS and tuberculosis in the NDMP (2012-2016:29,36). The negative consequences of the link between HIV and substance abuse place additional pressure on the business sector.

The Occupational Health and Safety Act (85 of 1993) states that employers of large as well as small companies are liable for managing the negative impact of substance abuse in the workplace, which includes denying employers under the influence access to the workplace. This Act further states that employees have a right to a safe work environment and that substance abuse can become an occupational hazard if not dealt with properly. Employees are themselves also legally bound by protocols governing substance abuse in the workplace. It is the responsibility of employees not to jeopardise the safety of colleagues through the use of substances (RSA, 1993a).

The Compensation for Occupational Injuries and Diseases Act (130 of 1993) holds employers and employees liable for safety precautions - employers are responsible for maintaining an alcohol- and substance-free workplace, and employees may not claim compensation from their employers to cover workplace damages and accidents resulting from their own serious and wilful misconduct because of substance intoxication (RSA, 1993b). 
The Employment Equity Act (55 of 1998) allows for testing of employees in the light of medical facts, employment conditions or inherent requirements of a job (RSA, 1998). This includes testing where employees operate heavy machinery and/or drive trucks, as well as testing to promote a substance-free workplace, and to protect employers, employees and the public from substance-related accidents that may occur (Services Seta, 2003a:28).

The Labour Relations Act (66 of 1995) makes it illegal to dismiss employees who are incapacitated or unable to work because of ill health resulting from substance dependency (RSA, 1995).

The South African Labour Guide (RSA, 2011:1-3) emphasises the importance of mutual respect between employers and employees, which also involves employment justice and the efficient operation of businesses. Alcoholism and substance dependence are regarded as kinds of incapacities and not as misconduct. The guide states that dismissal for unsatisfactory performance as a result of incapacity should be considered only after appropriate counselling and rehabilitation steps for employees have been considered and implemented.

The roles and responsibilities of employers and employees with regard to substance abuse and dependence in the workplace are clearly stipulated in the relevant Acts. A distinction is drawn between dependence, instances of incapacity and misconduct. Employers are legally obliged to facilitate rehabilitative measures and employees are obliged to refrain from misconduct. McCann et al. (2011:211) state that substance abusers should be disciplined and that substance dependence should be dealt with through treatment. McCann et al. (2011:9) believe, in fact, that "alcohol dependency should be de-stigmatised and alcohol abuse should be stigmatised".

\section{WORKPLACE}

Because of the detrimental effects of substance abuse and dependence on the workplace, and the legal obligations of employers to manage substance abuse and dependence problems effectively, employers need to commit time, energy and resources to deal with the problem (McCann et al., 2011:29). The workforce is regarded as a captive population already functioning in a structured working environment, which is considered the most appropriate and potentially successful setting to address the substance-abuse problems of employees (McCann et al., 2011:13).

Kemper (in Grobler et al., 2006:403) maintains that an appropriate belief system, supervisory practices and treatment facilities are important factors in retaining employees, before dismissal is considered. Such a belief system should hold, for example, that alcoholism is an illness and should be treated as such; that companies should offer appropriate assistance; that employees should take responsibility for seeking and accepting treatment; that early identification and treatment serve the best interests of employers and employees; and that diagnosis and treatment are the responsibility of trained professionals. Strategies recommended by Grobler et al. (2006:402) to combat substance abuse in the workplace include minimising stress and 
anxiety levels in the workplace and implementing rehabilitation policies and programmes. Guidelines for workplace policies are discussed below.

\section{Workplace policies}

The negative impact of substance abuse on the workplace and the legal obligations imposed on them have forced employers to develop workplace policies and practices to deal with the problem. Grobler et al. (2006:403-404) and McCann et al. (2011:211) refer specifically to the importance of clear policies and procedures for dealing with substance abuse and dependence in the workplace. Various policies have been implemented in South Africa to deal with substance abuse, especially with regard to alcohol problems and, to a lesser extent, to the problem of illicit substances. Despite the NDMP directives, few drug-related policies have been applied effectively (NDMP, 2012-2016:51-53).

Services Seta (2003a:41-42) proposes guidelines for a workplace substance-abuse policy in terms of which companies should provide the following workplace substance-abuse programmes:

- Education and awareness programmes;

- Prevention programmes;

- Programmes to promote openness, acceptance and care for affected employees;

- Treatment programmes (which are considered feasible in only very few companies).

Albertyn and Bhoola (2011:292-324) propose the following policy and procedural elements to address substance abuse in the workplace:

- Application of legislation and statutory authorisation in relevant Acts;

- Definition of roles and responsibilities of management, workers and union members in implementing appropriate policies;

- Information, education and training of personnel on all aspects of substance use and abuse;

- Information on warning signs of substance abuse and/or dependence in employees;

- Disciplinary procedures for dealing with substance-abuse problems;

- Management of suspected intoxication and testing protocols;

- Referral procedures aimed at advice and/or treatment;

- Counselling and treatment;

- Employee assistance programmes (EAPs).

The NDMP, legislation and guidelines for workplace substance-abuse policies indicate how employers should go about handling the problem of substance abuse and dependence in the workplace. Prevention, education, dissemination of information, and treatment, counselling and aftercare to combat substance abuse in South Africa, and more specifically in the workplace, are consistently highlighted as priority measures. 
Provision is made in the proposed policies and guidelines for training for managers in the early identification of substance-abuse problems, referrals to specialist agencies, use of registered in- and out-patient treatment centres, and intervention measures.

\section{INTERVENTION}

Support structures in the workplace in the form of employee assistance programmes (EAPs) and external specialist treatment services can assist employers with the identification and resolution of employees' substance-abuse problems.

McCann et al. (2011:279) refer to intervention measures that could be implemented depending on the stage of substance use. Knowledge of the characteristics of the different drinking categories or stages is needed to understand the risks faced by employers in counteracting the impact of substance abuse. McCann et al. (2011:3) describe the different categories of drinkers as social and moderate drinkers, heavy or excessive drinkers, alcohol abusers or problem drinkers, and dependent drinkers. The characteristics of these categories are: social drinkers - no excessive drinking; heavy or excessive drinkers - periodic binge drinking, inappropriate drinking patterns start to emerge; alcohol abusers - less control over use, solitary use begins, repeated promise failure; dependent drinkers - no control, obsessed with alcohol, life revolves around alcohol. Far more moderate, heavy and troubled problem drinkers than dependent drinkers are encountered in the workplace (Figure 2). An estimated $85 \%$ of employees consume alcohol, of whom $30 \%$ will be heavy drinkers, excessive drinkers and/or alcohol abusers, while approximately 6-16\% will be dependent drinkers (McCann et al., 2011:2,45).

\section{FIGURE 2}

\section{DRINKING CATEGORIES ACCORDING TO MCCANN ET AL. (2011:2)}

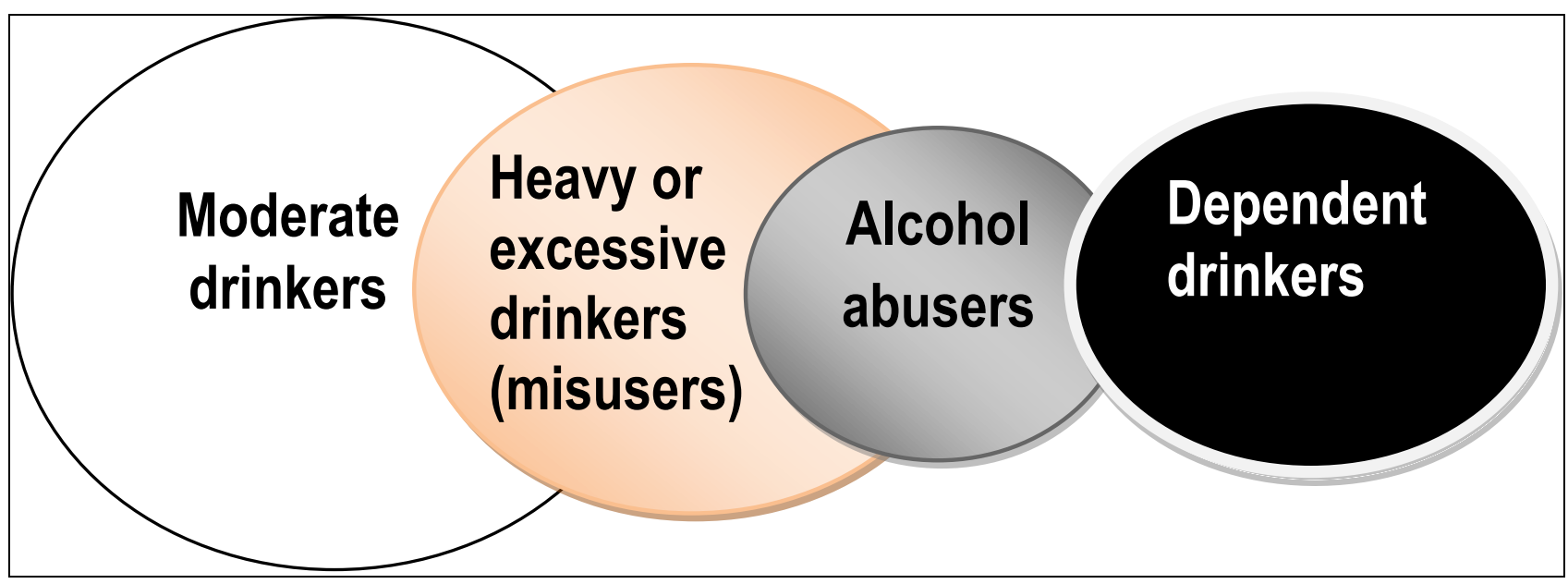

These different categories of drinkers correlate with the following stages of substance use as depicted by McCann et al. (2011:279).

TABLE 1

INTERVENTION MEASURES ACCORDING TO EACH LEVEL OF SUBSTANCE USE 


\begin{tabular}{|c|c|c|}
\hline $\begin{array}{l}\text { Stage/Category of } \\
\text { substance use }\end{array}$ & Intervention measure & $\begin{array}{l}\text { Intervention } \\
\text { measures }\end{array}$ \\
\hline $\begin{array}{l}\text { No use } \\
\text { Use (moderate/social drinkers) }\end{array}$ & $\begin{array}{l}\text { Prevention. } \\
\text { Prevention - no treatment required. }\end{array}$ & $\begin{array}{l}\text { PREVENTION } \\
\text { TREATMENT }\end{array}$ \\
\hline Misuse & $\begin{array}{l}\text { Prevention and brief/early } \\
\text { intervention. }\end{array}$ & Early intervention \\
\hline Abuse & $\begin{array}{l}\text { Brief intervention and in- or out- } \\
\text { patient treatment services. }\end{array}$ & and \\
\hline Dependence & $\begin{array}{l}\text { Detoxification and in- or out- } \\
\text { patient treatment services; } \\
\text { Sometimes mental health services; } \\
\text { Aftercare services/Continuing } \\
\text { support; } \\
\text { Harm reduction for individuals } \\
\text { with chronic dependence. }\end{array}$ & treatment \\
\hline
\end{tabular}

Table 1 shows that the main intervention measures are prevention and treatment including early or brief intervention and aftercare. In terms of the time relationships, Eberlein (2010:212-213) points out that prevention (referred to as primary care), and the entire treatment process (referred to as secondary care) comprise a relatively small proportion of the intervention programme. Aftercare is regarded as the longest of the recovering phases and referred to as a life-long process to establish a new lifestyle (Eberlein, 2010:220-227; Hitzeroth \& Kramer, 2010:114-115). The time relationships in the care and treatment process mentioned by Eberlein (2010:213) are illustrated in Figure 3.

Eberlein (2010:208-220) refers to aftercare as 95\% of the solution, with a life-long challenge to develop and maintain a new life style and achieve self-fulfilment. This is only possible through the assistance of those involved in the prevention, treatment and aftercare programme as well as those people involved in the life-long recovering process (Eberlein, 2010:215). The importance of professional support and support from self-help groups such as Alcoholics Anonymous (AA) and Narcotics Anonymous (NA) to remain abstinent are emphasised by Doweiko (2006:373), Eberlein (2010:54-55), Hitzeroth and Kramer (2010:114-115), McCann et al. (2011:256) and SANCA (2011a:90-92. 
FIGURE 3

\section{TIME RELATIONSHIPS IN THE CARE AND TREATMENT PROCESS}

(Eberlein, 2010:213)

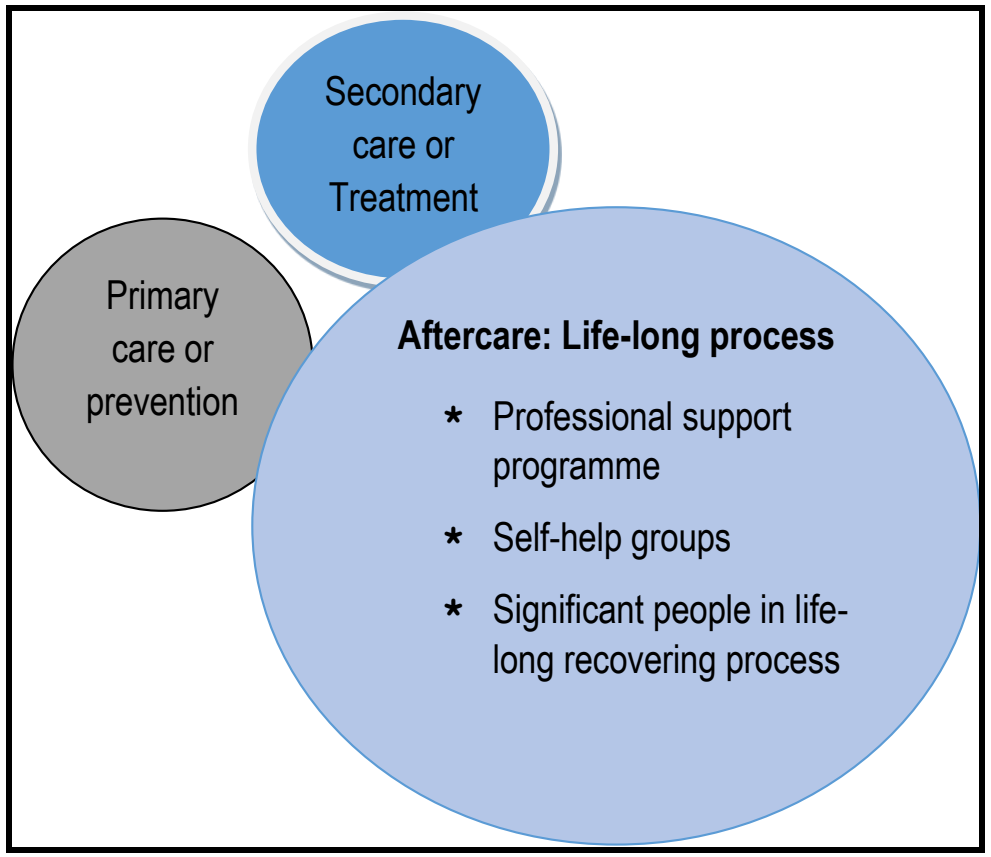

The main intervention measures - i.e. prevention and treatment comprising assessment, treatment programmes and aftercare - are discussed below.

\section{PREVENTION}

A key change in the new NDMP (2012-2016:3) is the shift from a supply reduction approach to a primary prevention and demand reduction approach. Reducing the need for substances through, for example, the prevention of and education on the use of substances is advocated in the new NDMP (2012-2016:21). Findings also indicate that substance abuse in the workplace can be prevented by raising awareness among employees about the impact of substance abuse on workplace performance, and by providing assistance and/or offering appropriate services to employees in need of intervention (ASBTDC, 2011:2). Prevention in the context of substance abuse is defined as a proactive process that creates and reinforces conditions that promote healthy behaviours and lifestyles such as activities to prevent or delay the onset of substance-use disorders (McCann et al., 2011:278).

McCann et al. $(2011: 276,278)$ consider the workplace to be the ideal environment for disseminating prevention messages on substance abuse. Prevention programmes targeting the whole workforce can prevent or dissuade employees from using substances at risky levels. Targeting selected groups in the workforce for prevention programmes is also important, especially with regards to occupational groups at risk. Services Seta (2003a:41-42) recommends the inclusion of prevention, awareness and education programmes in workplace substance-abuse policies. Measures are thus needed to prevent individuals, groups and communities from engaging in substance abuse and developing dependence. 


\section{Treatment}

Treatment of substance abuse problems in the workplace can be dealt with through inhouse corporate staff involvement by means of an EAP (Carroll \& Buchholtz, 2000:481) and/or by using external resources. The employer or EAP staff member may decide to refer problem cases for treatment to medical professionals, acute hospital care, detoxification treatment or treatment at a rehabilitation facility such as an in- or outpatient treatment centre (Eberlein, 2010:53-54; McCann et al., 2011:245-250). In-house intervention measures, with specific reference to the role of employee assistance programmes in dealing with substance abuse and dependence in the workplace, are discussed next followed by a discussion on specialist treatment and rehabilitation facilities.

\section{In-house intervention}

The treatment of employees experiencing substance-abuse problems is considered crucial, yet McCann et al. (2011:228-237) recommend 'treating the company' before attending to the problems of employees. Treatment of a company involves changing possible resistance towards a substance-abuse workplace policy; education of the entire workforce including management, employees and shop stewards; assessment of the problem as well as its causes; implementation of possible solutions including disciplinary measures; and the involvement of external service providers such as social workers. The key role of EAPs in dealing with substance abuse and dependence is confirmed by various sources such as Dalton, Hoyle and Watts (2006), Grobler et al. (2006), McCann et al. (2011), Roman (2002) and Services Seta (2003b).

\section{Employee assistance programmes}

Initially, EAPs grew rapidly worldwide (Roman, 2002:198), but gradually their impact declined in the USA, possibly because funding and federal support were withdrawn; research on workplace interventions for alcohol problems was discouraged; infrastructure for workplace referrals was neglected; and reluctance to address substance abuse in the workplace grew because of stigmatisation (Roman, 2002:197-200). Research findings also indicate a decline in satisfaction with the outcome of EAP referrals in the USA. The number of EAPs with which private substance-abuse treatment centres had referral relationships dropped significantly from seven EAPs to two EAPs in 1998 (Roman, 2002:203-204).

Dalton et al. (2006:374) state that EAPs have recently become popular in the USA once again, with most major corporations offering assistance to their employees. These EAPs are designed to assist employees who experience personal problems, including substance-abuse problems. The Kemper Insurance Companies (in Grobler et al., 2006:403-404), one of the first organisations in the USA to implement a formal EAP policy, state that the main aim of an EAP is to retain potential alcoholic employees by assisting them to prevent the development of the condition to a point where they are unemployable.

Grobler et al. (2006:397) refer to the growing number of EAPs in South Africa and attribute this trend to the early identification of substance-abuse problems, employer 
motivation of EAP employees to continue treatment, and follow-up and monitoring to minimise relapses. The Employee Assistance Professionals Association (EAPA) of South Africa defines an EAP as follows:

“...a worksite-based programme designed to assist in the identification and resolution of productivity problems associated with employees impaired by personal concerns including, but not limited to: health, marital, family, financial, alcohol, drug, legal, emotional, stress, or other personal concerns which may adversely affect employee job performance" (Services Seta, 2003b:5).

An EAP is thus considered a support structure in the workplace that can assist employees with problem solving, while at the same time enhancing productivity. However, limitations in EAPs have also been identified. For example, the discrepancy between the prevalence of substance abuse in the workplace and the low identification rate of substance-abuse problems is ascribed to an inability in EAPs to identify employees with such problems. The estimates by the South African Chamber of Mines indicate that the Chamber's identification rate of substance abuse in the workplace is $1 \%$, and this occurs mainly at hospitals where employees have been referred for problems other than substance-abuse problems (McCann et al., 2011:289). Various other reasons are given for the low identification rate, such as that most problem drinkers go undetected; reduced work performance develops gradually and is therefore not easily measurable; and identifying alcohol problems among low-to-moderate drinkers is difficult, because the signs and symptoms are less visible than with dependent drinkers (McCann et al., 2011:289). According to Walker and Shain (in McCann et al., 2011:289), this low identification rate indicates the inherent inability of EAPs to identify employees with drinking problems.

McCann et al. (2011:286) caution against supervisors in the workplace acting as counsellors and diagnosing employees with substance-abuse problems. Grobler et al. (2006:403-404) state that training of management staff in the early identification of substance-abuse problems, as well as referrals to an appropriate treatment facility at the earliest possible stage, will most likely deliver better end results. Such a proactive approach from employers will benefit themselves as well as employees.

Roman (2002:207-208) argues that workplace intervention should be reconstructive; that training should be given to EAP staff on the basics of substance-abuse intervention; that workplace personnel should not endeavour to induce behaviour change in substanceabuse employees; and that employees with substance-abuse problems should be referred to appropriate specialists. Goodman (2007:16-17,121) stresses the importance of specialist social workers in treating substance abuse and dependence in the workplace and adds that social workers have the necessary techniques and skills to engage effectively with clients who have substance-abuse problems. Ray Jones, Chair of the British Association of Social Workers, also believes that the core values and competencies of social workers are needed when working with substance abusers (Goodman, 2007:7). An EAP is thus regarded as an important support structure in the workplace to assist employees with substance-abuse problems; however, it is 
consistently recommended that substance-abuse intervention should be handled by specialists.

\section{Specialist treatment}

The importance of prevention and early intervention in cases of substance dependence is emphasised by Grobler et al. (2006) and McCann et al. (2011). Figure 2 shows that far more moderate, heavy and troubled problem drinkers than dependent drinkers are encountered in the workplace. Early identification and intervention while in the stage of moderate, heavy and troubled drinking are regarded as far more successful than treatment once dependence has developed (McCann et al., 2011:13). According to Grobler et al. (2006: 403-404), early diagnosis and treatment benefit not only employees but also employers.

Treatment of dependence is a long-term process - Eberlein (2010:53) states that there is not an instant cure nor an instant treatment for dependence. Eberlein (2010:158-160) and Hanson, Venturelli and Fleckenstein (2009:498-499) suggest observance of the following principles when selecting a suitable treatment programme:

- Treatment should be voluntary;

- Treatment should be individualised;

- Treatment should be accessible;

- Treatment should be holistic and address multiple problems and needs of clients;

- Continuous monitoring and evaluation of and adjustments to the treatment plan should take place;

- Treatment should last long enough to have a significant effect on the dependency - a period of roughly three months is recommended;

- Counselling and medication are important elements of the treatment;

- Treatment should include detoxification (if necessary) as part of the therapeutic programme;

- Treatment should be followed up with long-term aftercare and support and should make provision for relapses;

- Treatment should make provision for HIV and AIDS testing and counselling.

Treatment of clients with substance-abuse problems is usually conducted in phases comprising assessment, therapeutic treatment and aftercare (Hitzeroth \& Kramer, 2010:95-115) and is discussed in more detail below.

\section{Assessment}

\section{Therapeutic assessment}

Comprehensive assessment of a client's substance-abuse problems should be conducted by evaluating the client's work performance and history, as well as his or her medical and substance-abuse history. Various questionnaires are available for screening for 
possible dependence (Hanson et al., 2009: 497; McCann et al., 2011:331-338; Stevens \& Smith, 2005: 137-144; Van Wormer \& Davis, 2008: 208-209), of which only a few are mentioned here, such as the Alcohol Use Disorders Identification Test (AUDIT), which is widely accepted and commonly used in South Africa; the CAGE and TWEAK TESTS for alcohol dependence; the Drug Use Disorder Identification Test (DUDIT), which was developed as a parallel instrument to the AUDIT to identify possible drug dependence; and the Drug Abuse Screening Test (DAST), which also screens for drug dependence.

Assessment tools are facets of the diagnostic process and may be used either in conjunction or separately, depending on the assessing party's preferred methodology. These tools are freely available to social workers, medical professionals and people involved in human resource management. Limitations of these screening procedures include possible ambivalence of clients towards completing the questionnaires; possible under-reported substance consumption behaviour; and possible inconsistent administration of the questionnaires (McCann et al., 2010:156-158). It is therefore recommended that the diagnosis of substance abuse and dependence should be left to specialists (Grobler et al., 2006:403).

\section{Medical assessment}

Medical examination includes comprehensive medical assessment, drug testing, and medical guidance and assistance to monitor health and prevent illness. Risks to medical and mental health, and possible deliberate self-harm, violence or suicide, also need to be assessed. In emergencies an intervention should involve either referring the client to a general practitioner or the emergency unit of a local hospital (Hitzeroth \& Kramer, 2010:104). The key role of the occupational health professional is discussed in detail in McCann et al. (2011:261-275). Medical and health services also include HIV and AIDS testing and counselling because of the link between substance abuse and HIV and AIDS (SANCA, 2011a:127-128; SANCA, 2011b:58).

When clients stop using substances, withdrawal symptoms may develop, which can range from minor to life-threatening conditions. Managing withdrawal symptoms depends on the severity of the condition and may require detoxification. Hitzeroth and Kramer (2010:118) refer to detoxification as a medically supervised programme to assist patients experiencing withdrawal after substance abuse. Detoxification is considered an essential element in the treatment programme and should be discussed, evaluated and administered early in the assessment phase (Eberlein, 2010:158-160; Hitzeroth \& Kramer, 2010:120). The main objectives of detoxification are to treat the bodily imbalances caused by substance abuse; to alleviate the toxicity that results from substance abuse, and to wean the nervous system from the dependence (Eberlein, 2010:21-22; Hitzeroth \& Kramer, 2010:118; McCann et al., 2011:245). A medically trained healthcare professional should therefore be involved in the assessment, withdrawal and detoxification phase of the treatment (Hitzeroth \& Kramer, 2010:118; McCann et al., 2011:247). Detoxification is an integral part of the therapeutic programme and should not be administered in isolation. 


\section{Therapeutic treatment programmes}

Various authors - including Abadinsky (2011), Eberlein (2010), Goodman (2007), Hanson et al. (2009), Hitzeroth and Kramer (2010), McCann et al. (2011), Miller and Weisner (2002), SANCA (2011a), SANCA (2011b), Stevens and Smith (2005), and Van Wormer and Davis (2008) - list a range of therapeutic treatment programmes, only a few of which are discussed here. In this regard, Smith and Capps (2005:349) refer to a multidimensional approach in dealing with dependence. The general agreement in literature sources is that the choice of programme will depend on the needs and personal circumstances of the client as well as the available resources of the treatment facility (Abadinsky, 2011; Eberlein, 2010; Hanson et al., 2009; Hitzeroth \& Kramer, 2010; McCann et al., 2011; Stevens \& Smith, 2005).

The main aim of therapeutic treatment is to stop the harm caused by substance abuse, to prevent further health and social harm related to continuing substance abuse, and to help the client regain a sober and balanced lifestyle. Eberlein (2010:158-160) and Hanson et al. (2009:498-499) have identified important principles for selecting a suitable treatment programme and ensuring effective treatment. McCann et al. (2011:254) maintain that treatment should be goal directed, comply with basic human rights requirements and adhere to evidence-based practices. The following programmes are examples of evidence-based treatment programmes and are discussed briefly.

The Minnesota model advocates the disease concept, namely that substance dependence is the result of a disease with a physiological origin (Hitzeroth \& Kramer, 2010:113-114; SANCA, 2011b:24). The model focuses on the implementation of the 12-Step programme proposed by Alcoholics Anonymous (AA), family therapy, peer group support, group therapy and education on substance dependence (Hitzeroth \& Kramer, 2010:113-114).

The Matrix Intensive Outpatient Treatment Programme (Matrix IOP) comprises models and methods taken from numerous treatment approaches. The effects of the Matrix IOP have been evaluated frequently and reveal a significant reduction in substance abuse (Eberlein, 2010:161; McCann et al., 2011:255; SAMSHA, 2011:1). The Matrix IOP involves an evidence-based treatment approach and includes substance-abuse education; individual, family and group therapy; relapse prevention; and aftercare services. A strengths-based and motivational interviewing approach, cognitive behavioural therapy and the 12-Step programme are integral to the Matrix IOP (Eberlein, 2010:160-163; McCann et al., 2011:254-255).

Motivational enhancement therapy (MET) is a client-centred approach aimed at initiating behavioural change, motivating clients to engage in treatment, and guiding clients through the process of recovery. This approach is based largely on motivational interviewing techniques. An empathetic, non-confrontational and reflective listening approach is followed, and clients are encouraged to use their personal resources to promote behavioural change (Eberlein, 2010:162; McCann et al., 2011:254-255; SANCA, 2011b:25). 
Another approach, the strengths-based approach, has proven to be an essential component in the treatment of dependence (Van Wormer \& Davis, 2008:86). The basic principles of the strengths-based approach comprise honouring client self-determination, reacting to the client's stage of readiness, and tapping into the available resources of the client (Van Wormer \& Davis, 2008:86-88).

\section{Aftercare programme}

A structured aftercare programme is regarded as an important component in the treatment plan for substance dependence and contributes significantly to abstinence (Doweiko, 2006:368; Eberlein, 2010:211; Hitzeroth \& Kramer, 2010:114-115; McCann et al., 2010:257). The Prevention of and Treatment for Substance Abuse Act, 70/2008 (RSA, 2008:8), describes aftercare as on-going professional support to a client after formal treatment has been completed and is aimed at enabling the client to maintain sobriety and personal growth, and enhance his or her self-reliance and proper social functioning. Aftercare is designed and carried out with the assumption that treatment does not end with the completion of the formal treatment programme.

The goals of the aftercare programme should include relapse prevention, assisting the client to maintain the gains made in the treatment, to establish and monitor "the habit of sobriety", and to develop his or her full potential (Doweiko, 2006:373; Eberlein, 2010:216-220; Hitzeroth \& Kramer, 2010:115; McCann et al., 2010:257). Eberlein (2010:208-227) discusses aftercare in detail and particularly refers to the importance of developing the individual's potential during this phase. Physical healing to cure the damage to health; intellectual development as preparation for the demands of returning to the workplace; social development to take a stance in a society in which sobriety is not the norm; and the development of competencies to cope in the economic world these are but a few of the lifestyle changes necessary to remain abstinent. The importance of involving significant role players including the employer in the reintegration process is particularly stressed (Eberlein, 2010:215). A strong support network, regular visits to treatment counsellors, involvement in a sustainable quality aftercare programme and dedicated implementation of major lifestyle changes by the client are regarded as critically important in reducing the chances of relapse (Eberlein, 2010:208-227; Hitzeroth \& Kramer, 2010:114-115; McCann et al., 2011:256-257).

\section{REHABILITATION FACILITIES}

Various rehabilitation facilities are available for the treatment of substance dependence such as halfway house facilities, corporate in-house facilities, and in- and out-patient treatment facilities (Eberlein, 2010:53-54; Hitzeroth \& Kramer, 2010:110-113; McCann et al., 2011:248-250). In- and out-patient treatment centres generally follow the previously mentioned phases, namely specialist assessment, therapeutic treatment programmes and an aftercare programme.

In- and out-patient treatment centres are regulated by a number of Acts, including the Prevention of and Treatment for Substance Abuse Act (70 of 2008), the Non-Profit Organisations Act (71 of 1997), the Social Service Professions Act (110 of 1978) and 
relevant Labour Acts (SANCA, 2011a:106; SANCA, 2011b:43). The treatment programmes are based on minimum service standards for in- and out-patient treatment centres, and the norms and standards of the National Department of Social Development.

In- and out-patient treatment centres use the services of multidisciplinary teams consisting of social workers specialising in substance abuse therapy, medical professionals, psychiatrists, psychologists and spiritual counsellors. Services provided by these centres include comprehensive therapeutic assessment and treatment, medical assessment and treatment, and aftercare services. Treatment programmes may include the Minnesota model, the Matrix IOP model and motivational enhancement therapy (MET). Support for, and assistance to, family members of the substance-dependent person is included as part of the treatment. EAP services, HIV and AIDS testing including pre- and post-test counselling, as well as community prevention and awareness programmes are also provided (SANCA, 2011a:17-22; SANCA, 2011b:58-59).

Consideration of both in- and out-patient treatment facilities can provide an overall picture and serve as a guideline for selecting the most appropriate facility. The choice will depend on the needs and preferences of the client, the severity of the dependence, the cost implications for the company as well as for the employee (client), and logistical constraints (Eberlein, 2010:53; Hitzeroth \& Kramer, 2010:111-113; McCann et al., 2011:248-249).

\section{Out-patient treatment}

An out-patient treatment facility is described as a non-residential community-based facility where service users (clients) are required to attend therapy sessions on a regular basis for a specific period of time. Specialist rehabilitation programmes are offered by professional staff who provide a holistic service (RSA, 2008:10; SANCA, 2011a:108).

Treatment ranges from daily activities to once-a-week meetings at the clinic (McCann et al., 2011:249; SANCA, 2011a:17-19; Stevens \& Smith, 2005:179; Van Wormer \& Davis, 2008:112). The average duration of the programme ranges from two months to 12 months, which includes aftercare group sessions commencing after conclusion of the individual therapy treatment phase (McCann et al., 2011:249; SANCA, 2011a:63; Van Wormer \& Davis, 2008:112). The primary advantages of out-patient treatment are the lower cost factor and clients' being able to continue working while in treatment, and to continue functioning within their family environment for the treatment period. The disadvantages are that clients continue to be exposed to stressors and triggers that can stimulate cravings (McCann et al., 2011:249). Treatment costs are usually not covered by medical aid funds.

\section{In-patient treatment}

In-patient treatment is described as treatment where patients remain in a residential facility for the duration of the treatment, usually for a minimum period of 28 days (McCann et al., 2011:248-249; SANCA, 2011b:58-59; RSA, 2008:10; Stevens \& Smith, 2005:176). The primary advantages of in-patient treatment are the controlled environment, which enables regular observation and assessment of clients' progress, 
distance from stressors and cravings, and intensive treatment for severe cases. Disadvantages include the higher costs, although in-patient treatment is often covered by clients' medical aid funds, if available. Also, the simulated and institutionalised environment may be difficult for some clients to relate to, and they may experience feelings of vulnerability when returning to 'normal life' (McCann et al., 2011:248-249).

Despite the existence of in- and out-patient treatment services, the most recent report of the South African Community Epidemiology Network on Drug Use (SACENDU) indicates a lower referral rate nationwide by employers for treatment in comparison with some other sources of referral as illustrated in Table 2 (SACENDU, 2012b:2). Likewise, the source of payment indicates a similar tendency nationwide, that is, the payment rate by employers is lower in comparison with other sources (SACENDU, 2012a). SACENDU reflects statistics from all nine provinces in South Africa for the period JulyDecember 2011 and includes data from both in- and out-patient treatment centres (SACENDU, 2012a; 2012b).

TABLE 2

SOURCE OF REFERRAL RATE (\%)

\begin{tabular}{|l|c|c|c|c|c|c|}
\hline Source & *WC & *KZN & *EC & $* \mathrm{CR}$ & $* \mathrm{GT}$ & *NR \\
\hline Self/Family/Friends & $47 \%$ & $40 \%$ & $31 \%$ & $39 \%$ & $55 \%$ & $41 \%$ \\
\hline Work/Employer & $6 \%$ & $21 \%$ & $6 \%$ & $24 \%$ & $10 \%$ & $13 \%$ \\
\hline Social services/Welfare & $20 \%$ & $5 \%$ & $3 \%$ & $16 \%$ & $11 \%$ & $11 \%$ \\
\hline $\begin{array}{l}\text { Health professionals } \\
\text { (doctor/psychiatrist/nurse) }\end{array}$ & $10 \%$ & $5 \%$ & $54 \%$ & $8 \%$ & $5 \%$ & $13 \%$ \\
\hline Hospital/Clinic & $3 \%$ & $2 \%$ & $1 \%$ & $1 \%$ & $1 \%$ & $1 \%$ \\
\hline Court/Correctional services & $5 \%$ & $2 \%$ & $1 \%$ & $3 \%$ & $7 \%$ & $6 \%$ \\
\hline Schools & $5 \%$ & $13 \%$ & $4 \%$ & $8 \%$ & $5 \%$ & $4 \%$ \\
\hline Church/Religious body & $2 \%$ & $1 \%$ & $1 \%$ & $1 \%$ & $1 \%$ & $1 \%$ \\
\hline Other e.g. radio & $2 \%$ & $9 \%$ & $<1 \%$ & $1 \%$ & $3 \%$ & $5 \%$ \\
\hline
\end{tabular}

*WC - Western Cape *KZN - KwaZulu-Natal *EC - Eastern Cape

$* \mathrm{CR}-$ Central Region (comprising Free State, Northern Cape, North West)

*GT - Gauteng

*NR - Mpumalanga and Limpopo

A discrepancy thus exists between the prevalence rate and the identification and referral rate of substance abuse problems in the workplace. See the discussion above on the prevalence of substance abuse in the workplace and also compare the low identification rate reported by the Chamber of Mines. Furthermore, according to the UNODC (2012:4), fewer than one in five persons who need treatment for substance dependence actually receives it. In other words, numerous employees with substance-abuse problems are not detected nor attended to, and few employers make use of specialist treatment centres for employees. 


\section{TREATMENT OUTCOMES}

The treatment of dependence can be as successful as the treatment of other chronic diseases such as diabetes, hypertension and asthma, if done professionally to meet the needs of clients (Hanson et al., 2009:498; Hitzeroth \& Kramer, 2010:187; Van Wormer \& Davis, 2008:38-39).

Successful rehabilitation (Goodman, 2007:83) depends not only on the treatment but also on clients' willingness to actively engage and commit. Retaining clients in a treatment programme for a sufficient period of time is needed to enable treatment processes to have an effect. The National Treatment Agency report (2005) on "Retaining clients in drug treatment" in Goodman (2007:90) identifies useful best practices for retaining treatment:

- A personal touch and handwritten letters to clients will most likely motivate them to return for treatment;

- Personal approaches, handwritten letters and phone calls will most likely improve the attendance of individuals in group programmes;

- Clear messages on what the treatment programme entails and what is expected of clients in the treatment process will most likely have a reassuring effect on them. It has been found that by spending only 15 minutes on clarifying client expectations of out-patient treatment increased client returns in one study by $40 \%$.

Findings both from "real world" field studies and controlled clinical experiments reveal that treated clients show major reductions in alcohol and substance use for at least six months after completion of their treatment programme. Evaluation results indicate improved medical and psychological functioning, improved earnings from employment, and substantial reduction in HIV and AIDS risk behaviours and substance-related crimes. Findings also indicate that clients who receive more services, and in particular more professional services, exhibit the best outcomes (Miller \& Weisner, 2002:42).

Slaymaker and Owen (2006:352-353) reported significant gains after in- and out-patient treatment had been implemented with employee substance abusers. Improvements between the time of treatment and one year later were reported on absenteeism, problem days and the need for disciplinary action on the job. Almost $65 \%$ of the sample continued to work for the same employer, thus indicating the investment value of treatment for employers.

The effectiveness of treatment is discussed at length by Van Wormer and Davis (2008:26-39). According to these authors, the effectiveness of treatment can be measured by evaluating the reduction in healthcare needs, the extent of lower dependence, lower crime rates and successful employment. There is evidence that substance-abuse treatment reduces abuse and leads to improvements in employment, lower criminal activity, social adjustment and the better use of healthcare facilities (Stevens \& Smith, 2005:355). Gossop and colleagues (in Goodman, 2007:89) conducted a major research study on drug treatment in Britain, namely the National Treatment Outcome Research Study, and reported significant treatment benefits. Regarding crime 
rates, research on reconvictions following treatment shows a reduction of $24 \%$ for all offences after one year, $29 \%$ after two years and 50\% after five years. Research findings further reveal that "maximum" aftercare reduced crime by $90 \%$ compared to "minimum" aftercare, which reduced crime by 57\% (Goodman, 2007:82,89).

However, some substance-dependent persons are less fortunate and struggle to remain abstinent. They have difficulty in recovering - they experience repeated relapses, numerous rehabilitation admissions, numerous treatment episodes, exposure to different specialists, huge financial expenditure and little success. Hitzeroth and Kramer (2010:209) advocate the implementation of evidence-based interventions with proven track records to counteract these setbacks. These authors have compiled a list of prerequisites and guidelines for effective treatment outcomes that include a variety of interventions to ensure longer-term recovery and the development of a supportive network comprising family, friends, professionals and colleagues (Hitzeroth \& Kramer, 2010:209-215).

Significant treatment benefits have been reported with findings indicating that clients who receive more services, and in particular more professional services, have the best outcomes. Limitations in the success rate of rehabilitation can be countered through prevention and proactive measures, early identification and rapid referral of problems for specialist treatment. In other words, a supportive network and collaborative approach between employers and treatment centres are needed.

\section{CONCLUSION}

This article set out to highlight the huge impact of substance abuse on the workplace, on the one hand, and the available specialist resources to deal with substance-abuse problems, on the other. However, despite the havoc caused by substance abuse in the workplace, the problem often receives scant attention.

The legal demands on employers to manage substance-abuse problems in the workplace, include implementing counselling and rehabilitation measures, before dismissal of substance-dependent employees should be taken into account. The employers' dilemma is thus twofold. Firstly, employees are not permitted to work when under the influence of a substance, and secondly, employees with substance dependence are entitled to opportunities for counselling and rehabilitation programmes. In both instances employers face added expenses as a result of reduced production and absenteeism because of the treatment programme. Rehabilitation as the first legal obligation therefore needs to be beneficial to both employers and employees and requires careful evaluation by employers and treatment centres.

HIV and AIDS and substance abuse incur considerable costs for employers. Given the link between HIV and AIDS and substance abuse, both these issues need to be addressed simultaneously in order to ensure successful intervention.

The workplace culture is often not conducive to combating substance abuse in the workplace, and consequently cultivation of a working environment favourable to a healthier lifestyle regarding substance use should be promoted. Awareness, education 
and prevention programmes should receive priority attention as indicated throughout this literature review.

EAPs as support structures in the workplace are considered an ideal source for identifying and referring substance-abuse problem cases to appropriate facilities for specialist treatment. However, their inability in practice to identify substance-abuse problems and to refer cases for specialist treatment are regarded as serious shortcomings. Specialist resources are available to assist employers in dealing with substance abuse in the workplace, yet, these resources remain under-utilised.

\section{RECOMMENDATIONS}

A situation analysis of substance abuse and the workplace should be conducted to determine the specific needs of employers in addressing substance abuse in the workplace. Also, employers' views on a collaborative approach between employers and treatment centres should be explored to tackle the problem of substance abuse in the workplace.

\section{REFERENCES}

ABADINSKY, H. 2011. Drug use and abuse: a comprehensive introduction $\left(7^{\text {th }} \mathrm{ed}\right)$. Belmont: Wadsworth Cengage Learning.

ALBERTYN, C. \& BHOOLA, U. 2011. Proposed substance abuse policy and procedural agreement. In: McCANN, M., HARKER BURNHAMS, N.H., ALBERTYN, C. \& BHOOLA, U. Alcohol, drugs and employment $\left(2^{\text {nd }}\right.$ ed $)$. Claremont: Juta \& Co Ltd).

ANON. 2009. The naked truth - Statistics (SA \& GLOBAL). [Online] Available: http://www.tnt.org.za/index.php/ption=com_content\&view=article \&id=21\&Itemid=51 [Accessed: 15/03/2011].

ASBTDC (ARKANSAS SMALL BUSINESS AND TECHNOLOGY DEVELOPMENT CENTER). 2011. Arkansas drug free workplace: Facts and figures about drugs and alcohol in the workplace. [Online] Available: http://asbtdc.ualr.edu/drug free/facts.asp [Accessed: 24/02/2011].

BARNETT, T. \& WHITESIDE, A. 2006. AIDS in the twenty-first century: disease and globalization $\left(2^{\text {nd }}\right.$ ed). New York: Palgrave Macmillan.

CARROLL, A.B. \& BUCHHOLTZ, A.K. 2000. Business \& society: ethics and stakeholders management $\left(4^{\text {th }}\right.$ ed). Cincinnati: Thomson Learning.

CDA (Central Drug Authority). 2010/2011. Central Drug Authority annual report. Department of Social Development. Pretoria: Government Printer.

CRESWELL, J.W. 2003. Research design: qualitative, quantitative, and mixed methods approaches $\left(2^{\text {nd }}\right.$ ed). Thousand Oaks: Sage Publications.

DALTON, M., HOYLE, D.G. \& WATTS, M.W. 2006. Human relations $\left(3^{\text {rd }} \mathrm{ed}\right)$. Mason: Thomson South-Western. 
DOWEIKO, H.E. 2006. Concepts of chemical dependency $\left(6^{\text {th }}\right.$ ed). Belmont: Thomson Brooks/Cole.

EBERLEIN, R. (ed). 2010. Lifestyle changes to beat addiction: a guide to drug-free living. Randburg: Knowers Publishing (Pty) Ltd.

GOODMAN, A. 2007. Social work with drug and substance misusers: transforming social work practice. Wiltshire: Learning Matters Ltd.

GROBLER, P., WÄRNICH, S., CARRELL, M.R., ELBERT, N. \& HATFIELD, R.D. 2006. Human resource management in South Africa $\left(3^{\text {rd }}\right.$ ed). London: Thomson Learning.

HANSON, G.R., VENTURELLI, P.J. \& FLECKENSTEIN, A.E. 2009. Drugs and society $\left(10^{\text {th }}\right.$ ed $)$. London: Jones and Bartlett Publishers.

HITZEROTH, V. \& KRAMER, L. 2010. The end of addiction. A comprehensive South African guide. Cape Town: Human \& Rousseau.

ICAP (International Center for Alcohol Policies). 2013. Alcohol and the workplace. The ICAP BLUE BOOK: Practical guides for alcohol policy and prevention approaches. Module 22. [Online] Available: http://www.icap.org. [Accessed: 10/01/2013].

McCANN, M., HARKER BURNHAMS, N.H., ALBERTYN, C. \& BHOOLA, U. 2011. Alcohol, drugs and employment $\left(2^{\text {nd }}\right.$ ed). Claremont: Juta \& Co Ltd.

MILLER, W.R. \& WEISNER, C.M. (eds). 2002. Changing substance abuse through health and social systems. New York: Kluwer Academic/Plenum Publishers.

NDMP (NATIONAL DRUG MASTER PLAN). 2013-2017. Department of Social Development. Pretoria: Government Printer.

PARRY, C.D.H. \& BENNETTS, A.L. 1998. Alcohol policy and public health in South Africa. Cape Town: Oxford University Press.

PELSER, I. 2011. (admin@sancalowveld.co.za) 11 Feb. 2011. ETTEx Network: The future of drug testing.

REPUBLIC OF SOUTH AFRICA (RSA). 1978. Social Service Professions Act 110 of 1978.

REPUBLIC OF SOUTH AFRICA (RSA). 1993a. Occupational Health and Safety Act 85 of 1993.

REPUBLIC OF SOUTH AFRICA (RSA). 1993b. The Compensation for Occupational Inquiries and Diseases Act 130 of 1993.

REPUBLIC OF SOUTH AFRICA (RSA). 1995. The Labour Relations Act 66 of 1995.

REPUBLIC OF SOUTH AFRICA (RSA). 1996. Constitution of the Republic of South Africa Act 108 of 1996. 
REPUBLIC OF SOUTH AFRICA (RSA). 1997. Non-Profit Organizations Act 71 of 1997.

REPUBLIC OF SOUTH AFRICA (RSA). 1998. The Employment Equity Act 55 of 1998.

REPUBLIC OF SOUTH AFRICA (RSA). 2008. Prevention of and Treatment for Substance Abuse Act 70 of 2008.

REPUBLIC OF SOUTH AFRICA (RSA). 2011. The South African Labour Guide. [Online] Available: http://www.labourguide.co.za/workplace-discipline/code-of-goodpractice-dismissal-general-461 [Accessed: 24 February 2011].

ROMAN, P.M. 2002. Missing work: the decline in infrastructure and support for workplace alcohol intervention in the United States, with implications for developments in other nations. In: MILLER, W.R. \& WEISNER, C.M. (eds) Changing substance abuse through health and social systems. New York: Kluwer Academic/Plenum Publishers.

ROSE, S.J. \& ZWEBEN, A. 2002. Interrelationship of substance abuse and social problems. In: MILLER, W.R. \& WEISNER, C.M. (eds) Changing substance abuse through health and social systems. New York: Kluwer Academic/Plenum Publishers.

SACENDU (South African Community Epidemiology Network on Drug Use). 2012a. Phase 32. SACENDU Research Brief, 15(2).

SACENDU (South African Community Epidemiology Network on Drug Use). 2012b. SACENDU Report back meetings - November 2012. Monitoring alcohol and drug trends: January - June 2012. Phase 32. Tygerberg.

SAMSHA (SUBSTANCE ABUSE AND MENTAL HEALTH SERVICES ADMINISTRATION CENTER FOR SUBSTANCE ABUSE TREATMENT). 2011. Counsellor's treatment manual: Matrix intensive outpatient treatment for people with stimulant use disorders. [Online] Available: http://www.kap.samsha.go/ products/manuals/matrix/index.htm. [Accessed: 22/07/2011].

SANCA (South African National Council on Alcoholism and Drug Dependence). 2011a. Out-patient treatment manual. SA: s.n.

SANCA (South African National Council on Alcoholism and Drug Dependence). 2011b. In-patient treatment model for substance abuse. SA: SANCA National.

SERVICES SETA. 2003a. Toolkit: Managing substance abuse in the workplace. SA: S.n.

SERVICES SETA. 2003b. Toolkit: Employee Assistance Programmes and the law in South Africa. SA: s.n.

SLAYMAKER, V.J. \& OWEN, P.L. 2006. Employed men and women substance abusers: job troubles and treatment outcomes. Journal of Substance Abuse Treatment, 31:347-354. 
SMITH, R.L. \& CAPPS, F. 2005. Research and contemporary issues. In: STEVENS, P. $\&$ SMITH, R.L. Substance abuse counselling: theory and practice $\left(3^{\text {rd }}\right.$ ed). Upper Saddle River: Merrill Prentice Hall)

STEVENS, P. \& SMITH, R.L. 2005. Substance abuse counselling: theory and practice $\left(3^{\text {rd }}\right.$ ed). Upper Saddle River: Merrill Prentice Hall.

UNODC (United Nations Office on Drugs and Crime). 2012. World drug report. United Nations Publication, Sales No. E. 12. XI. 1. [Online] Available: http:www.unodc. org/documents/data-and-analysis/WDR2012/WDR_2012_web_small.pdf [Accessed: 12/01/2013].

VAN DYK, A. 2005. HIV/AIDS care \& counselling: a multidisciplinary approach ( $3^{\text {rd }}$ ed). Cape Town: Pearson Education.

VAN WORMER, K. \& DAVIS, D.R. 2008. Addiction Treatment. A strengths perspective $\left(2^{\text {nd }} \mathrm{ed}\right)$. Belmont: Thomas Brooks/Cole.

WHO (WORLD HEALTH ORGANIZATION). 2011. Global status report on alcohol and health. Switzerland: WHO Library Cataloguing-in-Publication Data.

Ms Breggie Smook, PhD student, Social Worker, SANCA Nelspruit; Dr Marie Ubbink, Prof Elma Ryke, Prof Herman Strydom, Department of Social Work, North-West University (Potchefstroom Campus), Potchefstroom, South Africa. 